\title{
Robot Beroda Perambat Dinding Berbasis Mikrokontroler ATmega 2560 Dilengkapi Kendali Nirkabel dan Penghindar Rintangan
}

\author{
Eko Didik Widianto, Ufan Alfianto*), R.Rizal Isnanto \\ Program Studi Sistem Komputer, Fakultas Teknik, Universitas Diponegoro \\ Jl. Prof. Soedarto, SH, Kampus Undip Tembalang, Semarang, Indonesia 50275
}

\begin{abstract}
This research developed a mobile wall climbing robot prototype using 4 DC motors as its driver and a suction tube. It can avoid obstacles. This robot uses Arduino Mega 2560 as its controller board. The robot's weight is 747 grams. The suction tube produces a suction force of $7.815 \mathrm{~N}$ capable of holding the robot load in a stall vertical position using $12 \mathrm{~V}$ of voltage. The robot able to crawl down and horizontal, but still can not climb vertically. The robot is able to receive a command of motion manually from a $2.4 \mathrm{GHz}$ wireless joystick. In automatic mode, the robot can avoid obstacles using the HC-SR04 proximity sensor. This research also shows the relationship between suction force and the given voltage of $\mathrm{DC}$ brushless motor and its throtle value.
\end{abstract}

Keywords: Wall climbing robot; Arduino Mega 2560; Wireless control; Suction tube; Suction force

\begin{abstract}
Abstrak - Penelitian ini mengembangkan sebuah purwarupa robot perambat dinding beroda dengan 4 buah motor DC sebagai penggerak dan sebuah tabung hisap serta dapat menghindari rintangan. Robot ini menggunakan Arduino Mega 2560 sebagai papan kontrolernya. Bobot robot adalah 747 gram. Tabung hisap menghasilkan gaya hisap sebesar 7,815 $N$ yang mampu menahan beban robot dalam posisi diam vertikal di tegangan $12 \mathrm{~V}$. Robot mampu merambat turun dan mendatar, namun masih tidak bisa naik vertikal. Robot mampu diberikan perintah gerak secara manual dari tombol joystick playstation nirkabel 2,4 GHz. Di mode otomatis, robot dapat bergerak menghindari rintangan menggunakan sensor jarak HC-SR04. Dalam penelitian ini juga ditunjukkan hubungan antara gaya hisap dengan nilai tegangan motor DC brushless dan nilai throtlenya.
\end{abstract}

Kata Kunci: Robot perambat dinding; Arduino ATmega 2560; Kendali nirkabel; Tabung hisap; Gaya hisap

\section{Pendahuluan}

Banyak model robot diciptakan dengan fungsi khusus untuk membantu pekerjaan manusia, seperti robot pelayan surat dengan identifikasi RFID [1], robot manipulator pemindah dan penyeleksi barang berdasarkan warna [2] serta robot pelayan pembersih debu menggunakan IoT [3]. Robot ini dilengkapi dengan beragam sensor, aktuator, link, logika kontroler dan media komunikasinya, misalnya kontrol melalui

*) Penulis korespondensi (Ufan Alfianto)

Email: ufanalfianto@gmail.com bluetooth [4], pengikut garis dengan kontrol PID[5] dan fuzzy untuk motor DC brush maupun brushless [6],[7] serta kontrol PI berbasis neural-fuzzy hibrida adaptif [8].

Salah satu model robot adalah robot perambat dinding (wall climber). Robot perambat dinding ini mampu berjalan di dinding dengan derajat kemiringan higga $90^{\circ}$ seperti cicak. Tantangan di robot jenis ini adalah bagaimana robot dapat merambat di bidang vertikal dengan menahan beratnya dan payload-nya yang berlawanan dengan gaya gravitasi.

Pengembangan robot perambat dinding dapat diklasifikasikan berdasarkan penggerak dan metode menempel. Sistem penggerak di robot dapat menggunakan roda, kaki (manipulator) dan tracked seperti tank. Robot beroda dapat digunakan di permukaan rata, membutuhkan daya yang lebih rendah dibandingkan tipe manipulator dan tracked serta dapat bergerak lebih cepat [9]. Robot berkaki dapat lebih efisien bergerak di permukaan dinding yang tidak biasa [10], sedangkan tipe tracked dapat berjalan di permukaan kasar dan licin [11].

Di tipe robot beroda, beragam metode penempelan dikembangkan, di antaranya dengan medan magnet [12], metode flip [13], dan tabung penghisap [14]-[16]. Robot magnetik hanya bisa menempel di permukaan ferromagnetik [12]. Beardsley dkk. [13] mengembangkan VertiGo yang memiliki rangka dan dua baling-baling dari serat karbon yang dipasang di bagian punggungnya untuk mendorong ke arah dinding dan mendorong ke atas sehingga dapat membuat gerakan membalik (flip) yang mampu melawan gravitasi. Penggunaan rangka karbon ini memerlukan biaya besar. Penggunaan tabung penghisap dikembangkan di robot perambat dinding dengan biaya lebih murah yang dikembangkan oleh peneliti [14]-[16].

Tipe pengendalian di robot beroda perambat dinding dengan tabung penghisap juga beragam. Metode pengendalian di robot [14]-[16] tersebut menggunakan diferensial dengan 2 roda. Robot dikendalikan secara manual menggunakan joystick berkabel [14],[15] dan nirkabel $2.4 \mathrm{GHz}$ [16].

Penelitian-penelitian tersebut di atas belum memberikan kemampuan gerak otomatis, misalnya saat ada rintangan di robot. Selain itu, penggunakan 2 motor penggerak menyulitkan bergerak di dinding yang licin. Artikel ini menjabarkan pengembangan robot beroda dengan penggerak 4 motor yang mampu merambat di dinding dan mampu menghindar rintangan di depan robot. Dengan menggunakan 4 roda penggerak dengan mode diferensial, robot akan mempunyai kemampuan 
Tabel 1. Komponen robot yang digunakan

\begin{tabular}{|c|c|c|}
\hline No & Nama Komponen & Fungsi \\
\hline 1 & Baterai & Catu daya utama \\
\hline 2 & Saklar SPDT & $\begin{array}{l}\text { Menghubungkan dan memutus } \\
\text { catu daya }\end{array}$ \\
\hline 3 & ESC 30 Ampere & $\begin{array}{l}\text { Mengatur kecepatan motor } \\
\text { Brushless }\end{array}$ \\
\hline 4 & Motor brushless & Mesin dari tabung hisap \\
\hline 5 & $\begin{array}{l}\text { Tranceiver joystick } \\
\text { playstation } 2,4 \mathrm{GHz}\end{array}$ & $\begin{array}{l}\text { Menerima perintah dari } \\
\text { joystick }\end{array}$ \\
\hline 6 & Motor DC & Aktuator robot \\
\hline 7 & Motor driver L293D & Pengendali motor DC \\
\hline 8 & Arduino Mega 2560 & Pengendali robot \\
\hline 9 & Sensor tegangan & Membaca tegangan catu daya \\
\hline 10 & $\begin{array}{l}\text { Sensor ultrasonik } \\
\text { HC-SR04 }\end{array}$ & $\begin{array}{l}\text { Membaca jarak objek untuk } \\
\text { penghindar rintangan }\end{array}$ \\
\hline 11 & LED & $\begin{array}{l}\text { Indikator mode kerja otomatis } \\
\text { dan tegangan kurang } 11 \mathrm{~V}\end{array}$ \\
\hline
\end{tabular}

bergerak di permukaan yang licin dan manuver gerak yang lebih baik daripada dengan 2 roda. Robot mempunyai mode gerak manual lewat joystick nirkabel $2.4 \mathrm{GHz}$ dan mode otomatis yang dapat menghindar rintangan sehingga dapat digunakan untuk medan dinding yang lebih bervariasi.

\section{Metode Penelitian}

Robot beroda ini dirancang agar mampu merambat dinding dan mempunyai dua mode kendali, yaitu manual dan otomatis. Kendali manual dilakukan oleh operator menggunakan joystick nirkabel 2,4 GHz, sedangkan kendali otomatis membuat robot bisa menghindari rintangan di depannya.

Robot beroda perambat dinding diimplementasikan dengan menggunakan papan Arduino Mega 2560 [17] dan lingkung pengembangan perangkat lunak menggunakan Arduino IDE 1.6.4 yang berjalan pada sistem operasi Windows 7. Robot menggunakan 4 buah motor DC sebagai aktuator penggeraknya. Motor DC terhubung dengan modul pengendali motor yang di dalamnya terdapat 2 buah IC L293D yang dapat mengendalikan 4 buah motor [18]. Mesin pengisap menggunakan sebuah motor brushless dan ESC 30 Ampere (Eelctronic Speed Control). Sensor ultrasonik HC-SR04 digunakan untuk pendeteksi rintangan di depan robot dengan deteksi mampu mencapai lebar 30 derajat dan jarak hingga $165 \mathrm{~cm}$ [19]. Komponen lain yang digunakan adalah sensor tegangan untuk mengukur tegangan baterai, LED sebagai indikator tegangan kurang dari 11 Volt dan mode kontrol yang digunakan, dan modul transceiver sinyal dari joystick playstation nirkabel 2,4 GHz. Joystick nirkabel yang digunakan untuk memberikan perintah ke robot di mode manual adalah joystick nirkabel 2,4 GHz buatan Sonny. Modul transceiver ini mempunyai jangkauan kendali dari joystick hingga 10 meter. Tabel 1 menunjukkan komponen robot dan fungsinya.

Pengujian yang dilakukan adalah pengujian gaya hisap, pengujian perambatan di dinding licin (kaca), pengujian perangkat masukan, dan perangkat luaran.

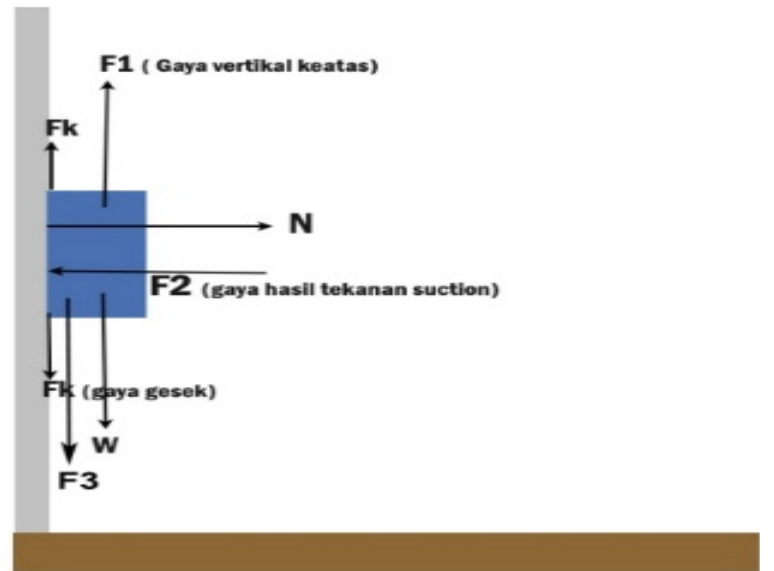

Gambar 1. Model gaya di robot beroda

Analisis sistem dilakukan menggunakan persamaan fisika di antaranya adalah persamaan gaya gesek, gaya berat dan gaya normal [20]. Model gaya dari robot ditunjukkan dalam Gambar 1. Kemampuan hisap dari tabung penghisap diteliti berdasarkan tegangan operasi yang diberikan ke motor brushless dan nilai throtle.

Berdasarkan Gambar 1 terdapat beberapa gaya yang berpengaruh, yaitu F1 atau gaya vertikal ke atas, F2 atau gaya hisap/suction, F3 atau gaya vertikal ke bawah, Fk atau gaya gesek dan $\mathbf{w}$ atau gaya berat dari robot itu sendiri. Dalam menjalankan robot terdapat 3 kondisi yang harus dipenuhi. Kondisi pertama adalah kondisi ketika robot akan naik yaitu kondisi saat gaya vertikal ke atas mampu mengalahkan gaya berat robot, gaya gesek dan gaya suction (Persamaan 1). Kondisi kedua adalah ketika diinginkan robot dalam kondisi diam menempel pada dinding. Kondisi yang harus dipenuhi adalah gaya suction dan gaya gesek harus mampu melawan atau sama dengan gaya normal dan gaya berat (Persamaan 2). Kondisi terakhir adalah ketika diinginkan robot mampu bergerak ke bawah di mana gaya berat ditambah gaya vertikal ke bawah mampu melawan gaya suction dan gaya gesek (Persamaan 3). Persamaan 1, 2, 3 akan digunakan dalam menganalisis kinerja robot dari tiga kondisi di atas.

$$
\begin{aligned}
& F 1>F k+F 2 \sin a+W \\
& F k+F 2 \sin a \geq W \\
& F k+F 2 \sin a<W+F 3
\end{aligned}
$$

\section{HASIL DAN PEMBAHASAN}

Diagram komponen robot beroda perambat dinding dengan mode kendali manual dan otomatis ditunjukkan dalam Gambar 2. Robot tersebut tersusun atas papan Arduino Mega 2560 (8), 4 buah motor DC (6), modul pengendali motor L293D (7), 1 buah motor brushless (4), ESC 30 A (3), sensor ultrasonik HC-SR04 (10), sensor tegangan (9), modul transceiver nirkabel joystick 2,4 GHz (5) dan 2 buah LED status (11). Robot dicatu dengan sumber tegangan baterai $12 \mathrm{~V}$ (1).

Hasil rakitan purwarupa robot beroda perambat dinding ditunjukkan dalam Gambar 3. Robot 


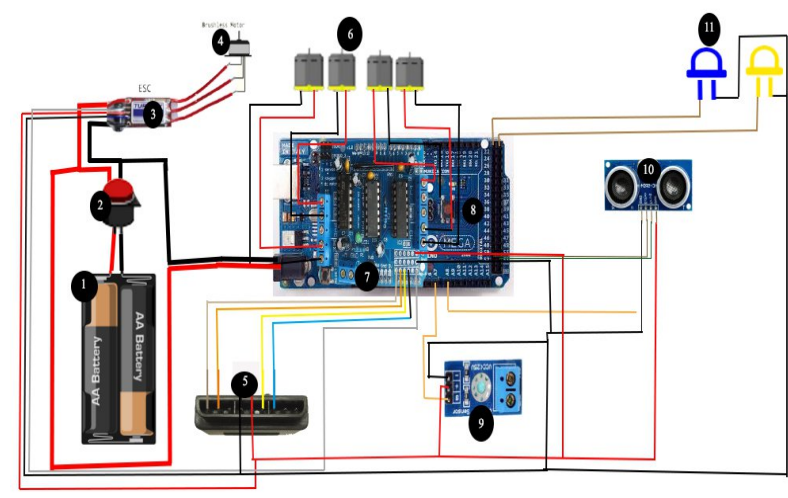

Gambar 2. Diagram komponen robot beroda perambat dinding

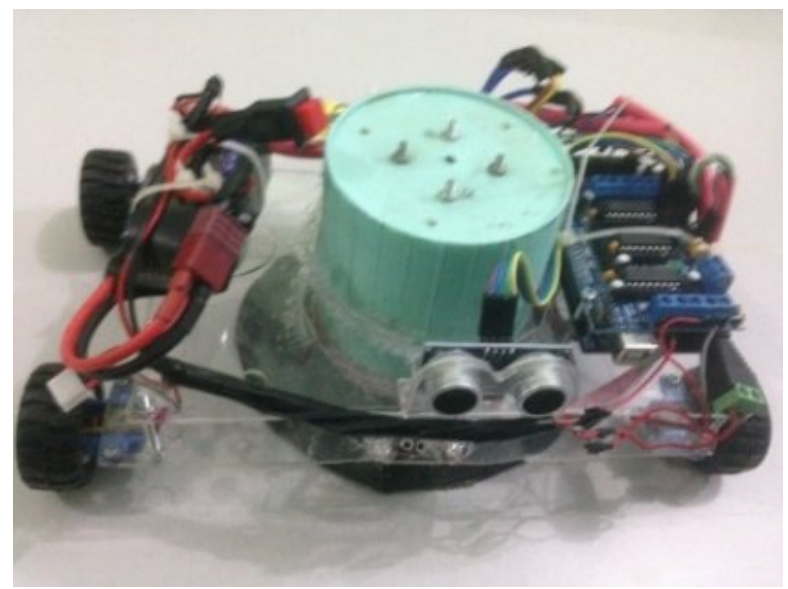

Gambar 3. Purwarupa robot beroda perambat dinding

mempunyai bobot 747 gram. Tabung hisap untuk menghisap permukaan agar robot mampu menempel di dinding diletakkan di tengah robot. Dalam tabung tersebut terdapat sebuah motor brushless yang dikendalikan kecepatannya oleh ESC 30A. Sensor jarak ultrasonik HC-SR04 diletakkan di depan robot untuk mendeteksi halangan saat mode otomatis. Empat roda penggerak digerakkan masing-masing oleh satu motor DC yang dapat diatur kecepatannya oleh kontroler. Modul pengendali motor berupa shield Arduino ditempelkan di atas papan Arduino Mega 2560.

Perangkat lunak yang ditanamkan di atas mikrokontroler ATMega ini meliputi pembacaan nilai sensor ultrasonik HC-SR04 untuk mendeteksi jarak halangan yang ada di depan robot, pembacaan sensor tegangan, penerimaan dan pengiriman data / kontrol nirkabel ke joystick, kontrol kecepatan motor brushless dalam tabung hisap, kontrol kecepatan motor penggerak DC, dan tampilan status LED untuk menunjukkan mode kerja sistem (manual/otomatis) dan indikator tegangan baterai saat kurang dari 11 Volt. Perintah joystick saat mode manual diterjemahkan sebagai gerak robot dan aktivasi motor brushless.

Pengujian sistem dilakukan dalam dua skenario, yaitu skenario pengujian subsistem tabung hisap dan subsistem perangkat masukan. Pengujian subsistem tabung hisap bertujuan untuk mengukur kemampuan hisap dan juga gaya lainnya yang berpengaruh terhadap

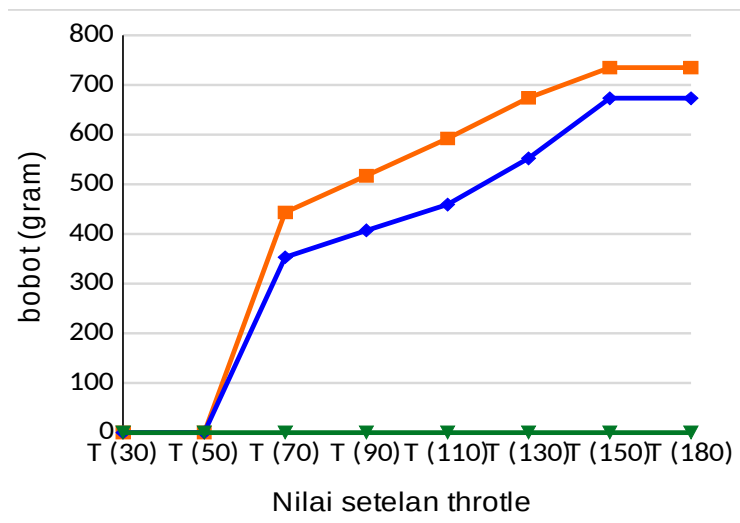

$\longrightarrow$ 11,1-12,6 10,7-11 $\longrightarrow$ - 10,7

Gambar 4. Hasil pengujian daya hisap robot

tabung hisap. Pengujian ini dilakukan dengan menggunakan timbangan digital untuk mengukur bobot akrilik, dan beban. Tabung hisap diletakkan dalam posisi vertikal menghadap akrilik untuk menghisap akrilik tersebut dengan penambahan bobot beban hingga batas maksimal beban yang mampu diangkatnya. Tegangan baterai dibagi dalam 3 jangkauan dan dipantau oleh sensor tegangan untuk melihat tegangan minimum yang diperlukan dan pengaruh tegangan terhadap gaya hisap. Kecepatan putaran motor brushless dinaikkan dengan mengatur nilai throtle untuk mendapatkan daya hisap lebih besar. Gambar 4 menunjukkan grafik hasil pengujian daya hisap terhadap nilai kendali throtle motor brushless dan tegangan operasi.

Hasil pengujian kemampuan hisap menunjukkan bahwa tegangan operasi akan menentukan daya hisap robot dengan nilai kendali throtle tertentu. Tegangan minimum robot untuk dapat menghasilkan daya hisap adalah 10.7 Volt, sedangkan saat tegangan kurang dari 10.7 Volt, mesin hisap tidak berfungsi. Dengan tegangan terukur 11.1-12,6 Volt, bobot minimal yang bisa diangkat adalah 407 gram dengan throtle 70, sedangkan bobot maksimalnya adalah 735 gram dengan throtle 150. Kemampuan hisap tidak bertambah meskipun throtle dinaikkan.

Dengan kemampuan mengangkat beban minimal 407 gram dan maksimal 735 gram, maka untuk mengangkat beban robot sebesar 747 gram dibutuhkan faktor lain yang mampu menguatkan kekuatan hisap dari tabung hisap, yaitu gaya gesek tabung hisap dan gaya vertikal ke atas oleh keempat motor DC. Dari hal tersebut di atas, robot tidak dapat memenuhi kondisi pertama seperti di Persamaan 1. Hasil percobaan menunjukkan robot tidak mampu bergerak vertikal ke atas karena gaya yang dihasilkan tidak cukup mengalahkan dari gaya berat, gaya gesek dan gaya hisap. Gaya F1 sebesar 0,1 N lebih kecil dari nilai $F k+F 2 \sin a+W$, yaitu sebesar $15,275 \mathrm{~N}$.

Kondisi kedua di Persamaan 2 dapat dipenuhi oleh robot, yaitu robot dalam kondisi diam menempel pada dinding dan bergerak horizontal. Kondisi yang 


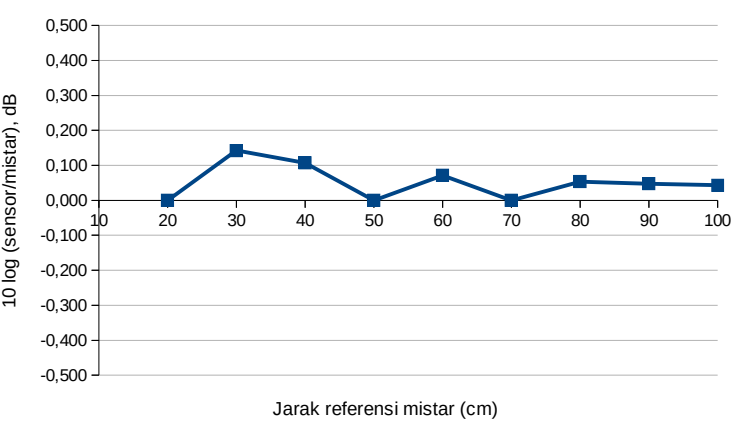

Gambar 5. Perbandingan pembacaan sensor jarak dan referensi

harus dipenuhi adalah gaya suction dan gaya gesek harus mampu melawan atau sama dengan gaya normal dan gaya berat. Gaya tempel sebesar $F k+F 2 \sin a$ atau 7,815 $\mathrm{N}$ lebih besar daripada nilai $\mathrm{W}$ atau berat total sebesar $7,47 \mathrm{~N}$.

Kondisi ketiga di Persamaan 3 juga dapat dipenuhi robot, yaitu robot mampu bergerak ke bawah. Kondisi yang harus dipenuhi adalah gaya berat ditambah gaya vertikal ke bawah mampu melawan gaya hisap dan gaya gesek. Gaya hisap dan gaya gesek $F k+F 2 \sin a$ sebesar 7,815 N lebih kecil daripada nilai $W+F 3$ sebesar $15,04 \mathrm{~N}$.

Pengujian subsistem perangkat masukan menguji pembacaan sensor ultrasonik HC-SR04, sensor tegangan dan kontrol pengguna melalui joystick nirkabel 2,4 GHz. Pengujian sensor HC-SR04 dilakukan dengan membandingkan nilai keluaran sensor dengan alat ukur pembanding yaitu mistar. Pengujian dilakukan sebanyak 10 kali pembacaan. Jarak yang dihitung adalah dari titik sensor berada dengan penghalang. Hasil pengujian menunjukkan bahwa sensor mempunyai kesalahan maksimal $1 \mathrm{~cm}$ dari jarak yang ditunjukkan oleh mistar atau akurasi minimal 96,67\% untuk jarak 10-100 cm. Gambar 5 menunjukkan grafik perbandingan jarak yang terbaca oleh sensor dengan jarak pada alat pembanding. Perbandingan kesalahan terbesar adalah $0,142 \mathrm{~dB}$ di jarak referensi $30 \mathrm{~cm}$ dengan selisih pembacaan $1 \mathrm{~cm}$.

Pengujian sensor tegangan bertujuan menguji akurasi sensor tegangan terhadap baterai yang digunakan. Pengujian dilakukan dengan membandingan hasil pembacaan sensor tegangan dengan multimeter. Hasil perbandingan pembacaan tegangan antara sensor tegangan dan multimeter adalah sensor tegangan memiliki akurasi pembacaan sebesar 97,04\% untuk tegangan 6,63-11,38 Volt. Gambar 6 menunjukkan diagram perbedaan pembacaan antara sensor tegangan dengan multimeter. Kesalahan pembacaan terbesar adalah $-0,147 \mathrm{~dB}$ di tegangan 11 Volt dengan selisih pembacaan $-0,38$ Volt.

Pengujian masukan lainnya adalah untuk menguji fungsional perintah kontrol dari joystick 2,4 $\mathrm{GHz}$ sampai jarak 10 meter. Perintah ini dilakukan dengan menekan setiap tombol perintah pada joystick nirkabel dan mengamati perilaku robot terhadap perintah yang diberikan tersebut. Tabel 2 menunjukkan

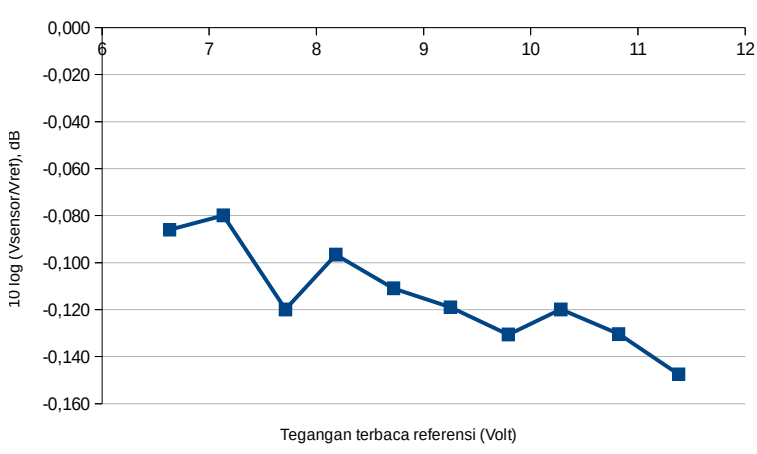

Gambar 6. Perbandingan pembacan tegangan sensor dan multimeter

Tabel 2. Hasil pengujian fungsional perintah joystick nirkabel 2,4 GHz

\begin{tabular}{cccc}
\hline No & Tombol & Fungsi tombol & Keterangan \\
\hline 1 & $\uparrow$ & Jalan lurus & Berhasil \\
2 & $\leftarrow$ & Belok kiri & Berhasil \\
3 & $\rightarrow$ & Belok kanan & Berhasil \\
4 & $\downarrow$ & Mundur & Berhasil \\
5 & $\bigcirc$ & Aktifkan motor & Berhasil \\
& brushless & \\
6 & $\square$ & Menonaktifkan & Berhasil \\
& & motor brushless & \\
7 & - & - & Tidak digunakan \\
8 & X & - & Tidak digunakan \\
9 & L1 & - & Tidak digunakan \\
10 & L2 & - & Tidak digunakan \\
11 & R1 & - & Tidak digunakan \\
12 & R2 & - & Tidak digunakan \\
13 & SELECT & Manual & Berhasil \\
14 & START & Automatis & Berhasil \\
15 & MODE & Mengaktifkan / & Berhasil \\
& & nonaktifkan joys- & \\
16 & & tick & Tidak digunakan \\
17 & LX & - & Tidak digunakan \\
& RY & - & Tidak digunakan \\
\hline \multicolumn{5}{r}{} & & - &
\end{tabular}

hasil pengujian fungsional pembacaan perintah lewat joystick saat mode robot manual.

Pengujian subsistem perangkat keluaran pada robot ini adalah untuk melihat perilaku LED sebagai indikator dan aktuasi motor DC di mode manual dan otomatis. Pengujian subsistem perangkat keluaran pada robot ini adalah untuk melihat perilaku LED sebagai indikator pemberitahuan kapasitas catu daya utama dan mode kerja yang digunakan oleh robot beroda perambat dinding. Pengujian LED indikator catu daya dilakukan dengan memberikan tegangan ke robot bervariasi dan terkontrol. LED harus menyala saat tegangan baterai kurang dari 11 Volt yang menunjukkan tegangan rendah. Saat sensor tegangan membaca nilai kurang dari sama dengan 11 Volt maka LED putih yang terpasang pada robot akan menyala berkedip, tetapi jika kondisi tegangan lebih dari 11 Volt maka LED akan mati.

Perilaku LED sebagai indikator mode robot telah berfungsi dengan baik. Pengujian fungsional ini dilakukan dengan mengatur mode kendali robot manual dan otomatis dengan menggunakan joystick. LED indikator akan aktif atau menyala ketika robot dalam 
kondisi mode otomatis dan akan mati ketika mode manual. Di mode otomatis, robot mengaktifkan sensor jarak HC-SR04 untuk deteksi halangan. Saat robot dalam kondisi mode manual maka LED yang berwarna biru tidak menyala, sedangkan ketika robot dalam kondisi mode otomatis maka LED akan menyala terus menerus sampai mode manual dijalankan kembali.

Pengujian keluaran terakhir adalah pengujian motor driver yang terhubung dengan motor DC dan roda yang berfungsi sebagai aktuator penggerak. Motor DC sebagai aktuator digerakkan dengan perintah sesuai yang diberikan oleh joystick. Hasil dari pengujian ini adalah semua tombol yang digunakan dapat bekerja sesuai dengan perintah, seperti tombol $\uparrow$ untuk menjalankan robot ke depan, tombol $\downarrow$ untuk menjalankan robot ke belakang, tombol $\rightarrow$ untuk memerintahkan robot agar berbelok ke kanan, tombol $\leftarrow$ untuk memerintahkan robot agar berbelok ke kiri, tombol START untuk masuk ke mode otomatis dan tombol SELECT untuk masuk ke mode manual, serta tombol $\mathbf{O}$ untuk menjalankan motor bruhsless dan tombol $\Delta$ untuk menonaktifkan motor brushless. Hasil lengkap dapat dilihat pada bagian lampiran (Tabel 6).

Pengujian keseluruhan sistem dilakukan dengan menggabungkan seluruh perangkat masukan dan keluaran menjadi suatu sistem robot perambat dinding. Pengujian fungsional yang dilakukan meliputi pembacaan sensor tegangan, pembacaan sensor ultrasonik HC-SR04 dan masukan dari joystick playstaion nirkabel $2,4 \mathrm{GHz}$ serta kondisi aktuator. Semua subsistem telah dapat berfungsi sesuai yang diinginkan seperti ditunjukkan di Lampiran (Tabel 7).

Robot beroda perambat dinding dengan menggunakan tabung penghisap ini telah mampu untuk menempel di dinding, seperti [14]-[16]. Dengan tabung penghisap tunggal, robot mampu menghasilkan gaya hisap 7,815 $\mathrm{N}$ yang mampu menahan beban total 747 gram, dibandingkan [16] dengan gaya hisap 5,5 N. Robot dapat dikendalikan oleh operator secara nirkabel menggunakan perintah joystick 2,4 GHz [16]. Mode gerak otomatis telah dapat dilakukan oleh robot dengan deteksi penghalang menggunakan sensor ultrasonik dengan kesalahan pembacaan jarak maksimal $1 \mathrm{~cm}$ [19]. Kendali diferensial pada robot dengan menggunakan 4 motor penggerak telah dapat dilakukan sehingga memungkinkan robot dapat bergerak di permukaan licin. Robot dapat bergerak di dinding licin (kaca) dengan arah horizontal dan menurun, namun belum mampu merambat ke atas. Kemampuan merambat ke atas dapat dilakukan menggunakan 2 tabung hisap aktif yang tersambung manipulator sebagai link-nya, seperti robot [2],[13]. Kontrol dan monitor robot selanjutnya dapat dilakukan dengan IoT [3] atau jalur nirkabel lainnya, seperti bluetooth [4]. Saat ini, robot masih menggunakan logika On-Off untuk kontrol otomatisnya. Dengan tambahan sensor yang tepat, robot dapat dikembangkan lebih lanjut untuk keperluan spesifik menggunakan logika kontrol PID [5], fuzzy [6],[7] atau neural-fuzzy hibrida adaptif [8].

\section{KESIMPULAN}

Robot beroda perambat dinding berbasis mikrokontroler ATMega 2560 telah mampu menempel pada dinding dengan bantuan tabung hisap yang di dalamnya terdapat motor brushless dan mampu menahan beban hingga 747 gram dengan sumber tegangan 12 Volt (Kondisi 2). Robot juga mampu untuk merambat turun karena gaya vertikal ke bawah ditambah gaya berat mampu melawan gaya hisap dan gaya gesek (Kondisi 3). Namun, robot tidak mampu memanjat vertikal karena gaya naik vertikal oleh aktuator motor DC tidak mampu melampaui gaya berat, gaya gesek dan gaya hisap (Kondisi 1).

Penelitian ini menunjukkan bahwa tegangan minimum untuk motor brushless adalah 10.7 Volt dan nilai throtle maksimalnya untuk menghasilkan gaya hisap maksimum adalah bernilai 150 . Sensor ultrasonik dan sensor tegangan cukup akurat untuk mengukur jarak dan tegangan, yaitu masing-masing dengan akurasi minimal 96,67\% dan 97,04\%. Robot dapat bekerja dalam mode manual yang dikontrol dengan joystick nirkabel sampai jarak 10 meter dan otomatis.

\section{Daftar Pustaka}

[1] S. Agustina. "Rancang Bangun Robot Pelayan Surat dengan Penunjuk Blok Alamat yang Diidentifikasi Menggunakan Tag RFID (Hardware)", Skripsi, Politeknik Negeri Sriwijaya, 2015.

[2] P. Prabanegara, R. Henggar, F. Noor, and E. Kurnia, "Rancang Bangun Robot Lengan Pemindah dan Penyeleksi Barang Berdasarkan Warna Berbasis Arduino Uno", Jurnal Energy, vol. 5, no. 2, 2016.

[3] A. Sentosa, D. Purwanto, and R. Dikairono. "Rancang Bangun Kendali Jarak Jauh Robot Servis Pembersih Debu Berbasis Internet of Things", Jurnal Teknik ITS, vol. 5, no. 2, pp. A185-A191, 2016

[4] O. Bettuang, I. G. A. P. R. Agung, and P. Rahardjo, "Pengendali Mobile Robot Melalui Bluetooth Berbasis Mikrokontroler AVR ATmega8 Dilengkapi Lengan dan Kamera", Jurnal Ilmiah SPEKTRUM, vol. 2, no. 2, pp. 79-84, 2015.

[5] M. Yusuf, "Implementasi Robot line Follower Penyiram Tanaman Otomatis Menggunakan Metode Proporsional-Integral Derivative Controller (PID)", semanTIK Vol. 2, No. 1, 2016.

[6] A. Mukti, O. D. Nurhayati, and E. D. Widianto, "Rancang Bangun Sistem Kontrol Robot Line Follower Menggunakan Logika Fuzzy", Jurnal Teknologi dan Sistem Komputer, vol. 3, no. 4, pp.536-543, $2015 . \quad$ doi: http://dx.doi.org/10.14710/jtsiskom.3.4.2015.536543.

[7] A. D. Yulianta, and S. P. Hadi, "Pengendalian Kecepatan Motor Brushless DC (BLDC) menggunakan Metode Logika Fuzzy", Jurnal Sains, Teknologi dan Industri, vol. 12, no. 2, pp. 248-254, 
2015.

[8] A. S. Wicaksono, "Perancangan dan Implementasi Sistem Pengaturan Kecepatan Motor BLDC Menggunakan Kontroler PI Berbasiskan NeuralFuzzy Hibrida Adaptif", Jurnal Teknik ITS, vol.5, no. 2, pp. F68-F74, 2016

[9] J. Xiao, and A. Sadegh,"City-climber: a new generation wall-climbing robots," ISBN 978-3902613-16-5, pp. 546, October 2007

[10] A. Sintov, T. Avramovich, A. Shapiro," Design and Motion Planning of an Autonomous Climbing Robot With Claws," Robotics and Autonomous System, vol. 59, no. 11, pp. 1008-1019, 2011

[11] A. Sekhar, A. Mary, S. N. Raju, A. G. Ravi, V. Sharma, G. Bala, "A Novel Design Technique To Develop A Low Cost and Highly Stable Wall Climbing Robot", 4th International Conference on Intelligent Systems, 2013.

[12] M. R. A. M. Zin, K. S. M. Sahari, J. M. Saad, A. Anuar, A. T. Zulkarnain, " Development of a Low Cost Small Sized In-pipe Robot," Procedia Engineering, vol. 41,pp. 1469-1475, 2012.

[13] P. Beardsley, R. Siegwart, M. Arigoni, M. Bischoff, S. Fuhrer, D. Krummenacher, D. Mammolo, and R. Simpson, "Vertigo- A Wall-
Climbing Robot including Ground-Wall Transition", Disney Research, 2015.

[14] K. Panchal, C. Vyas, D. Patel, "Developing the Prototype of Wall Climbing Robot," International Journal of Advance Engineering and Research Development, vol. 1, no. 3, April 2014.

[15] R. P. Putra, "Rancang Bangun Prototype Robot Pembersih Kaca", Skripsi, Universitas Diponegoro, 2014.

[16] E.P. Santoso, "Robot Pemanjat Dinding", Skripsi, Universitas Kristen Satya Wacana, 2014.

[17] "Arduino Mega." [Online]. Available: www.arduino.cc/en/Main/arduinoBoardMega 2560/. [Accessed: 07-Jul-2016].[4]

[18] L293x Quadruple Half-H Drivers (L293, L293D), Texas Instruments, 2016

[19] E. S. Purnomo, A. F. Rochim, and E. D. Widianto, "Handsight: Hand-Mounted Device untuk Membantu Tunanetra Berbasis Ultrasonic dan Arduino", Jurnal Teknologi dan Sistem Komputer, vol.3, no.1, pp.51-57, 2015. doi: http://dx.doi.org/10.14710/jtsiskom.3.1.2015.51-57.

[20] A. S. Lohat, "Gaya Gesek, Gaya Berat dan Gaya Normal" 2014. [Online]. Available: www.gurumuda.net. [Accessed: 30-Jun-2016]. 


\section{Lampiran}

Tabel 3. Hasil pengujian daya hisap robot

\begin{tabular}{cccccccccc}
\hline \multirow{2}{*}{ No } & Tegangan & \multicolumn{10}{c}{ Daya Hisap (gram) } \\
& ( volt ) & $\mathbf{T ~ ( 3 0 )}$ & $\mathbf{T ~ ( 5 0 )}$ & $\mathbf{T ~ ( 7 0 )}$ & $\mathbf{T ~ ( 9 0 )}$ & $\mathbf{T}(\mathbf{1 1 0})$ & $\mathbf{T ~ ( 1 3 0 )}$ & $\mathbf{T ~ ( 1 5 0 )}$ & $\mathbf{T}(\mathbf{1 8 0})$ \\
\hline 1 & $11,1-12,6$ & 0 & 0 & 364 & 452 & 522 & 614 & 735 & 735 \\
2 & $10,7-11$ & 0 & 0 & 353 & 407 & 459 & 552 & 673 & 673 \\
3 & $<10,7$ & 0 & 0 & 0 & 0 & 0 & 0 & 0 & 0 \\
\hline
\end{tabular}

Tabel 4 Hasil pengujian sensor jarak HC-SR04

\begin{tabular}{cccc}
\hline NO & $\begin{array}{c}\text { Mistar } \\
\text { (dalam cm) }\end{array}$ & Jarak sensor ultrasonik HC-SR04 (dalam cm) & 10 log $\frac{\text { Dsens }}{\text { Dref }}$ \\
\hline 1 & 0 & 0 & - \\
2 & 10 & 10 & 0 \\
3 & 20 & 20 & 0 \\
4 & 30 & 31 & 0,142 \\
5 & 40 & 41 & 0,107 \\
6 & 50 & 50 & 0 \\
7 & 60 & 61 & 0,072 \\
8 & 70 & 70 & 0 \\
9 & 80 & 81 & 0,054 \\
10 & 90 & 91 & 0,048 \\
11 & 100 & 101 & 0,043 \\
\hline
\end{tabular}

Tabel 5 Hasil pengujian sensor tegangan

\begin{tabular}{cccc}
\hline No & $\begin{array}{c}\text { Hasil pembacaan sensor } \\
\text { tegangan (dalam volt) }\end{array}$ & $\begin{array}{c}\text { Hasil pembacaan multime- } \\
\text { ter (dalam volt) }\end{array}$ & $10 \log \frac{\text { Vsens }}{\text { Vref }}$ \\
\hline 1 & 11,38 & 11 & $-0,147$ \\
2 & 10,82 & 10,5 & $-0,130$ \\
3 & 10,28 & 10 & $-0,120$ \\
4 & 9,79 & 9,5 & $-0,131$ \\
5 & 9,25 & 9 & $-0,119$ \\
6 & 8,72 & 8,5 & $-0,111$ \\
7 & 8,18 & 8 & $-0,097$ \\
8 & 7,71 & 7,5 & $-0,120$ \\
9 & 7,13 & 7 & $-0,080$ \\
10 & 6,63 & 6,5 & $-0,086$ \\
\hline
\end{tabular}

Tabel 6 Pengujian keluaran joystick playstation nirkabel 2,4 GHz dengan motor DC

\begin{tabular}{|c|c|c|c|c|}
\hline No & Tombol & Inisial tombol & Fungsi & Keterangan \\
\hline 1 & & ps2x.ButtonPressed(PSB_PAD_UP) & Motor maju & Berhasil \\
\hline 2 & $\uparrow$ & ps2x.ButtonReleased(PSB PAD UP) & Motor berhenti & Berhasil \\
\hline 3 & & ps2x.ButtonPressed(PSB_PAD_LEFT) & Motor belok kiri & Berhasil \\
\hline 4 & $\leftarrow$ & ps2x.ButtonReleased(PSB_PAD_LEFT) & Motor berhenti & Berhasil \\
\hline 5 & & ps2x.ButtonPressed(PSB_PAD_RIGHT) & Motor belok kanan & Berhasil \\
\hline 6 & $\rightarrow$ & ps2x.ButtonReleased(PSB__PAD_RIGHT) & Motor berhenti & Berhasil \\
\hline 7 & & ps2x.ButtonPressed(PSB_PAD_DOWN) & Motor mundur & Berhasil \\
\hline 8 & $\downarrow$ & ps2x.ButtonReleased(PSB_PAD_DOWN) & Motor berhenti & Berhasil \\
\hline
\end{tabular}


Tabel 7 Pengujian Sistem Keseluruhan

\begin{tabular}{|c|c|c|c|}
\hline No & Parameter & Hasil yang harus dipenuhi & Kesimpulan \\
\hline 1 & $\begin{array}{l}\text { Robot dapat dinyalakan } \\
\text { dengan menekan saklar on }\end{array}$ & $\begin{array}{l}\text { Semua sensor aktif, penerima sinyal } \\
\text { joystick playstation nirkabel } 2,4 \mathrm{GHz} \\
\text { aktif berkedip. Jika penerima sinyal } \\
\text { tidak dikenali maka LED pada } \\
\text { penerima sinyal akan terus berkedip }\end{array}$ & Terpenuhi \\
\hline 2 & $\begin{array}{l}\text { Robot mampu dikendalikan } \\
\text { dengan sistem kendali } \\
\text { manual }\end{array}$ & $\begin{array}{l}\text { Ketika tombol SELECT ditekan } \\
\text { maka robot dalam kondisi kendali } \\
\text { manual yang artinya robot } \\
\text { dikendalikan dengan joystick } \\
\text { playstation nirkabel } 2,4 \mathrm{GHz}\end{array}$ & Terpenuhi \\
\hline 3 & $\begin{array}{l}\text { Robot mampu dikendalikan } \\
\text { dengan sistem kendali } \\
\text { automatis }\end{array}$ & $\begin{array}{l}\text { Ketika tombol START ditekan maka } \\
\text { robot dalam kondisi pengendalian } \\
\text { automatis yang memanfaatkan sensor } \\
\text { ultrasonik HC-SR04 sebagai alat } \\
\text { indra }\end{array}$ & Terpenuhi \\
\hline 4 & $\begin{array}{l}\text { Sebagian tombol pada } \\
\text { joystick playstation nirkabel } \\
2,4 \mathrm{GHz} \text { dapat dioperasikan }\end{array}$ & $\begin{array}{l}\text { Total tombol pada joystick } \\
\text { playstation nirkabel } 2,4 \mathrm{GHz} \text { adalah } \\
14 \text { tombol, sedangkan yang memiliki } \\
\text { fungsi adalah } 9 \text { tombol, sisanya tidak } \\
\text { dihiraukan }\end{array}$ & Terpenuhi \\
\hline 5 & $\begin{array}{l}\text { joystick playstation nirkabel } \\
2,4 \mathrm{GHz} \text { dapat mengaktifkan } \\
\text { motor brushless pada tabung } \\
\text { hisap }\end{array}$ & $\begin{array}{l}\text { Tombol O pada joystick playstation } \\
\text { nirkabel } 2,4 \text { GHz dapat } \\
\text { mengaktifkan motor brushless } \\
\text { sehingga tabung hisap mampu } \\
\text { menghisap permukaan lintasan }\end{array}$ & Terpenuhi \\
\hline 6 & $\begin{array}{l}\text { Sensor tegangan mampu } \\
\text { membaca tegangan pada } \\
\text { catudaya utama }\end{array}$ & $\begin{array}{l}\text { Sensor tegangan yang terhubung pada } \\
\text { port A4 pada Arduino Mega mampu } \\
\text { membaca sensor dengan interval } 0-25 \\
\text { volt }\end{array}$ & Terpenuhi \\
\hline 7 & $\begin{array}{l}\text { Sensor ultrasonik HC-SR04 } \\
\text { mampu membaca kondisi } \\
\text { rintangan di depan robot }\end{array}$ & $\begin{array}{l}\text { Sensor ultrasonik HC-SR04 yang } \\
\text { terhubung pada port } 23 \text { untuk trig } \\
\text { dan } 22 \text { untuk echo mampu membaca } \\
\text { jarak rintangan yang ada di depan } \\
\text { robot }\end{array}$ & Terpenuhi \\
\hline 8 & $\begin{array}{l}\text { LED biru akan menyala } \\
\text { ketika robot dalam kondisi } \\
\text { kendali automatis }\end{array}$ & $\begin{array}{l}\text { LED biru yang terhubung pada port } \\
52 \text { akan menyala ketika tombol } \\
\text { START ditekan. LED dijadikan } \\
\text { sebagai indikator mode kendali }\end{array}$ & Terpenuhi \\
\hline 9 & $\begin{array}{l}\text { LED putih akan menyala } \\
\text { ketika tegangan dari catu } \\
\text { daya utama } \\
\text { memungkinkan }\end{array}$ & $\begin{array}{l}\text { LED putih yang terhubung pada port } \\
53 \text { akan menyala ketika sensor } \\
\text { tegangan mendeteksi tegangan } \\
\text { kurang dari sama dengan } 11 \text { volt }\end{array}$ & Terpenuhi \\
\hline
\end{tabular}

